\title{
EDITORIAL
}

\section{EN MEMORIA DE JOAQUÍN PEREIRA CANDEL}

\author{
Fernando Villar, José Ramón Repullo y Luis Ángel Oteo
}

Escuela Nacional de Sanidad. Instituto de Salud Carlos III. Ministerio de Sanidad y Consumo.

Hay hombres que luchan un día y son buenos
hay otros que luchan un año y son mejores
hay quienes luchan muchos años y son muy buenos
pero hay los que luchan toda la vida, esos son los imprescindibles.

Nos hemos quedado sin Quino. El pasado 24 de noviembre de 2003 falleció de forma súbita y prematura nuestro querido amigo y compañero Joaquín Pereira Candel, «Quino». De esta forma se ha truncado una brillante trayectoria profesional y personal, que ahora perdurará gracias al recuerdo de su persona y de su meritoria labor y a la continuación de la misma.

Joaquín había nacido en las tierras murcianas de Blanca el 22 de marzo de 1954 estableciéndose más tarde en La Adrada (Ávila), en las estribaciones de la impresionante Sierra de Gredos. Se licenció en Medicina y Cirugía en la Universidad Complutense de Madrid en 1978. Su vocación de servicio le llevó a ingresar en el Cuerpo de Inspección Sanitaria de la Administración Sanitaria de la Seguridad Social en 1982 Comenzó su actividad como Médico Inspector en Madrid y Sevilla. Posteriormente, fue Director Médico del Hospital de Valme (Sevilla). Completó su formación realizando el Máster en Salud Pública en la Ecole Nationale de Santé Publique de Rennes (Francia) en 1988.

Finalmente, llegó al Instituto de Salud Carlos III en 1990, primero a la Subdirec- ción General de Salud y poco después a la Escuela Nacional de Sanidad (ENS), donde por concurso era el Jefe de Área de Salud Internacional. Aquí desarrolló una intensa y fructífera actividad en la triple vertiente de docencia, investigación y asesoría. En el ámbito docente fue profesor y coordinador en numerosos cursos realizados en la ENS (Máster de Salud Pública, Máster de Administración Sanitaria, Programa de Epidemiología Aplicada de Campo, entre otros).

Es de destacar que fue el artífice y director del Diploma de Salud Internacional, curso evaluado y acreditado por TROPEDEUROP como core-course, del que se han cumplido ya nueve ediciones, y del Máster de Salud Internacional. Sin duda, éstos son sus cursos más preciados, que llevó a cabo con el cariño, entusiasmo, dedicación y el buen hacer que en él eran característicos.

Convencido de la importancia del trabajo en equipo, logró formar uno con sus entrañables compañeros del Departamento de Salud Internacional: Ricard Génova, Elena Álvarez, Cristina Campos, Maite Martín, Eduardo Fernández Zincke, Carmen Audera, Consuelo Morant, Marieta Iradier y un largo etcétera de personas que tuvieron la fortuna 
durante todos estos años de poder trabajar y aprender con él, con su ejemplo, con su estímulo, con su actitud y con su manera de entender las cosas. Buena prueba de su magisterio son los profesionales que actualmente trabajan en distintos organismos internacionales, como la Organización Mundial de la Salud y la Comisión Europea, o en los más variados países, como Mozambique o Estados Unidos (Escuela de Salud Pública de Harvard), que fueron colaboradores suyos y se formaron junto a él. Con ellos perdurará su labor.

Joaquín entendía claramente que el principal objetivo de la salud internacional era mejorar la salud de las poblaciones más desfavorecidas. Como él mismo señalaba, esta disciplina está adquiriendo una creciente importancia en un mundo que afronta profundos y rápidos cambios, y a la vez un mayor interés por sus amplias perspectivas de trabajo e investigación. Joaquín supo verlo con claridad y a ello dedicó sus mayores esfuerzos.

Su labor investigadora se plasma entre otras en su participación en el Programa BIOMED-2 de la Comisión Europea y en los proyectos sobre carga de enfermedad financiados por el Fondo de Investigación Sanitaria, la Fundación para la Investigación y Prevención del SIDA en España (FIPSE) y el Banco Interamericano de Desarrollo. También es de destacar su intervención en el proyecto europeo de la red ENEPRI (European Network of Economic Policy Research Institutes) financiado por el V Programa Marco de la Unión Europea.

Los estudios de carga de enfermedad han permitido relanzar el debate público sobre la racionalidad de las decisiones en política sanitaria, poniendo de manifiesto las diferencias en salud entre países y grupos sociales y contribuyendo a definir mejor las necesidades y las prioridades de salud de las poblaciones. Las investigaciones llevadas a cabo por Joaquín en este área van a servir para priorizar la financiación de la investigación sanitaria en España. Sirva esto como reconocimiento póstumo a su quehacer.

Para facilitar el uso de esta metodología, Joaquín desarrolló un programa informático (GesMor) de gestión de datos de mortalidad, morbilidad y discapacidad para el cálculo automatizado de los años de vida sanos perdidos, y lo difundió mediante talleres de capacitación en países iberoamericanos.

Sus investigaciones dieron lugar a numerosas publicaciones en libros y prestigiosas revistas nacionales e internacionales, entre ellas el Bulletin of the World Health Organization, en el que se recogen los principales resultados del proyecto BIOMED-2, la Revista de Administración Sanitaria, en la que obtuvo el premio al mejor artículo publicado en el año 2001, y la propia la Revista Española de Salud Pública.

Por último, señalar en su amplia actividad de asistencia técnica y asesoría, que fue consultor de la Organización Panamericana de la Salud y del Banco Mundial. En todas las partes del mundo donde tuvo la oportunidad de impartir su magisterio, y fueron muchas, dejó su fructífera impronta.

Pero la figura de Joaquín supera con creces su magnífico perfil profesional, sus cualidades personales eran admirables. Persona responsable, comprometida con los problemas del tiempo que le tocó vivir, amante de la naturaleza, con enorme honradez y rigor intelectual, trabajador infatigable, perseverante, ejemplo y maestro para todos los que le conocimos.

Desde que recibió el primer aviso este verano, llevó su enfermedad con extraordinaria entereza, disciplina y paciencia. Siempre junto a su inseparable Isabel Noguer, a quien damos nuestro cariño y apoyo.

Existe un epitafio en las afueras de Teruel que dice: Si nos olvidáis, será cuando real-

Rev Esp Salud Pública 2003, Vol. 77, N. ${ }^{\circ} 6$ 
mente moriremos. En este sentido, es importante el emotivo acto de homenaje a Joaquín realizado en su querida Escuela Nacional de Sanidad, durante el que se ha colocado una placa que da su nombre a un aula de la ENS y con la instauración de la «Lección Joaquín Pereira», que todos los años constituirá el perfecto colofón al Diploma de Salud Internacional. Pero no sólo con actos como éste, que por otra parte es merecido, se debe recordar a Joaquín, sino también a diario continuando y apoyando el magnífico trabajo desarrollado por él. En ello todos estamos comprometidos. 